Research Article

\title{
Flexural Behavior of Precast Concrete Segmental Box-Girders with Dry Joints
}

\author{
Shun Chai $\mathbb{D}^{1},{ }^{1}$ Tong Guo $\mathbb{D}^{\circ},{ }^{2}$ Zheheng Chen, ${ }^{3}$ and Jun Yang ${ }^{4}$ \\ ${ }^{1}$ School of Civil Engineering, Southeast University, Nanjing 210096, China \\ ${ }^{2}$ Key Laboratory of Concrete and Prestressed Concrete Structures of the Ministry of Education, Southeast University, \\ Nanjing 210096, China \\ ${ }^{3}$ College of Civil and Transportation Engineering, Hohai University, Nanjing 210098, China \\ ${ }^{4}$ School of Civil Engineering, Southeast University, Nanjing 210096, China \\ Correspondence should be addressed to Tong Guo; guotong@seu.edu.cn
}

Received 25 March 2020; Revised 17 October 2020; Accepted 23 October 2020; Published 5 November 2020

Academic Editor: Daniele Baraldi

Copyright (c) 2020 Shun Chai et al. This is an open access article distributed under the Creative Commons Attribution License, which permits unrestricted use, distribution, and reproduction in any medium, provided the original work is properly cited.

Precast concrete segmental (PCS) box-girders are widely used in bridge construction, while studies on flexural behaviors of PSC boxgirders with dry joints are insufficient. Six large-scale PCS box-girders with dry joints were tested to failure under two-point loading in this study. Strain increments, tendon forces, deflections at mid-span, and cracks were recorded during the tests. Multiple factors were investigated with regards to their influence on flexural performance of girders. It is found that most specimens failed due to the excessive force in tendons, while the specimen with external tendons failed due to concrete compressive crushing. Larger shear span ratio resulted in greater increase in tendon force and concrete strain during loading and, accordingly, the lowest ultimate flexural capacity. Lower concrete strength resulted in larger increase in concrete strain and tendon force during loading and relatively smaller deflection at failure. For the specimen with four segments, a significant increase in tendon force and smaller deflections at failure was observed as compared with specimen 1, though the failure load was similar. Numerical simulation is further conducted, where it is found that the area of prestressed tendon and the number of joints have a significant influence on ultimate flexural bearing capacity and deflection; besides, deflection control standard of PCS girders should be stricter than that of the integral cast girder. The corbel joints, in general, show better ultimate performance than the castle-shaped joints.

\section{Introduction}

Precast concrete segmental (PCS) girders have been widely applied in mid-/long-span bridges due to their rapid assembly, excellent quality control, low life-cycle cost, and mitigated environmental disturbance. In the past decades, extensive studies were conducted on PCS girder bridges concerning the shear strength of epoxy and dry joints with various geometries [1-5]. It was observed that the average shear strength in multiple-keyed dry joints is less than that in single-keyed dry joints in view of imperfections in occlusion of keys [1] and the failure of the epoxied joints was brittle [2]. Alcalde pointed out that as the number of shear keys increases, shear stress across the joint decreases [3]. Numerical evaluation of the shear behavior of a Ferro Casting Ductile
(FCD) metal shear key [4] indicated that a combination of high-quality concrete and higher prestressing force would be safer when a FCD shear key is applied in segmental dry joints. Additionally, it is observed that shear capacity of the joints increased by approximately $40 \%$ as the confining stress increased by $50 \%$ [5].

Besides, behavior of PCS girders with internal, external, or hybrid tendons [6-10] and performance of girder under different loading (i.e., pure bending and combined shear and bending) have been investigated, although currently, such studies are still limited. Yuan investigated the influence of two different loading types and indicated that three-point bending load could reduce the vertical deflection at the onset point of nonlinearity [7]. Jiang studied flexural behavior of precast segmental beams with hybrid tendons and revealed 
that flexural strength of fully segmental beams with hybrid tendons is $30 \%$ less than that of the monolithic beam [8]. The failure mode of dry joints is different from that of epoxied joints, and stirrups contribute little to the bearing capacity of the segmental interface under combined shear and bending; thus, the stirrups are not included as factors in this experiment [9].

More recently, steel fibers were used in PCS girders to increase shear strength and ductility [11-15]. Turmo [16] investigated unbonded precast segmental girders with steel fiber-reinforced concrete and found that conventional shear reinforcement is ineffective in the shear capacity test. Load bearing capacity of ultra-high-performance fiber-reinforced concrete structures with dry joints was investigated experimentally and theoretically [17]. Tests on precast segmental beams with an unboned carbon fiber-reinforced polymer (CFRP) tendon showed that stresses in the tendons in the ultimate loading condition were low, ranging from only about $66 \%$ to $72 \%$ of the nominal breaking tensile strength [18]. A parametric study was performed to investigate the influence of panel thickness, concrete strength, and bolt pattern on the performance of the fiber-reinforced beams [19].

However, more investigations are still needed to reveal the flexural behavior of PCS box-girders with dry joints, such as the influence of concrete strength, the number of shear keys, shear span ratio, odevity of the segment number, and hybrid use of tendons. Besides, comparison between precast segmental box-girders and monolithic ones requires further investigation, so as to develop a specific deflection control criterion for the precast girders and to improve bridge design. In this study, six large-scale PCS box-girders with dry joints were tested to failure under two-point loading. Strain increments, tendon forces, deflections at mid-span, and cracks were monitored and recorded during the tests. Multiple factors, such as concrete strength, odevity of the segment number and the number of shear keys, shear span ratio, and layout of tendons, were investigated with regards to their influence on the flexural performance of girders. Numerical models are developed and validated based on the test results, and the influences of other parameters not considered in the tests are investigated.

\section{Description of Stepwise Loading Tests}

2.1. Test Specimen. In this study, six PCS box-girders were manufactured with the length of $4 \mathrm{~m}$, being $1 / 8$ scaled of simply-supported girders used in the Jinghu high-speed railway [20], and the relatively large-scaled specimens guarantee the authentic representing of real structures. Characteristics of specimens are displayed in Table 1. Sustained loading was applied for more than one year prior to the tests [21]. The specimens except specimen 2 are made of C50 concrete with the mean compressive strength of 55.2 $\mathrm{MPa}$, while specimen 2 used C40 concrete with the mean cubic compressive strength of $44.3 \mathrm{MPa}$. Two bonded prestress strands were placed symmetrically in specimens 1 to 5, as shown in Figure 1, while specimen 6 adopted a hybrid tendon layout with two internally bonded and two externally unbonded ones, as shown in Figure 2. The nominal strength of all the strands is $1860 \mathrm{MPa}$, and the net cross-sectional area of strands is $139 \mathrm{~mm}^{2}$. An HRB400-grade hot-rolled ribbed bar with the diameter of $8 \mathrm{~mm}$ and the nominal yield strength $400 \mathrm{MPa}$ was used both for longitudinal reinforcements and transverse stirrups, and the stirrup spacing was $100 \mathrm{~mm}$ in all segments.

As shown in Figure 3, all the girders are symmetrically loaded at two points with a contact area of $300 \mathrm{~mm} \times 300 \mathrm{~mm}$. The distance from the center line of the steel plate to the support is $1.075 \mathrm{~m}$ except for specimen 4 (with the distance of $1.205 \mathrm{~m}$ ), and accordingly, the shear span ratio of specimen 4 is 3.09 while that of the other girders is 2.76. Girder segments in the pure bending zone are the focus of this study. EM sensors and vibrating wire strain gauges (VWSGs) were installed at the mid-span to measure the change in tendon forces and tensile strains, respectively. In addition, concrete strain gauges were pasted at the midspan with the distances of $60 \mathrm{~mm}, 180 \mathrm{~mm}$, and $325 \mathrm{~mm}$ to the lower girder surface, respectively. Displacement gauges were placed at the mid-span and two girder ends, as shown in Figure 4.

During the tests, the girders were subjected to increasing static load. Before the loading reached $120 \mathrm{kN}$ (i.e., the predicted yielding load), the load increment was $10 \mathrm{kN}$; thereafter, $5 \mathrm{kN}$ was adopted to better describe the nonlinearity in this stage. During the loading, joints between segments were gradually opening with cracks accumulating at the root of shear keys. Figure 5 shows specimens 1 and 4 under the final step loading, where significant joint opening could be observed. Besides, joints in the pure bending region showed larger opening than the others. When the loading approached the ultimate state, the sound of concrete crushing and spalling can be heard.

2.2. Results and Discussion. For specimens 1 to 5 , they were regarded failed when tendon forces approached the ultimate value (i.e., $260 \mathrm{kN}$ ), followed by the rapid increase in girder deflections. Note that the rate of deflection during the test ranged from $0.188 \mathrm{~mm} / \mathrm{min}$ (at the beginning) to $2.738 \mathrm{~mm} /$ min (at the end of test). Table 2 shows the original and final tendon forces during the tests. To avoid the sudden rupture of the tendons, the loading was not actually reached $260 \mathrm{kN}$, but stopped at $238.02 \mathrm{kN}$ to $258.79 \mathrm{kN}$ for specimens 1 to 5 . Figure 6 further shows the increase in tendon forces during the loading, where the data acquisition frequency was $0.1 \mathrm{~Hz}$. It is found that specimen 4 with larger shear span ratio had the fastest increase in tendon forces, while the change in specimen 6 is mild since there were another two external tendons in this specimen. Other specimens (i.e., specimens 2,3 , and 5) showed slightly faster increase in tendon forces than specimen 1 . For specimen 6 , the failure occurred when the compressive crushing appeared at the top flange of the girders, while due to the sufficient internal and external tendons, the final tendon forces were only about half of those in other specimens. Besides, there was an increase of $55.82 \mathrm{kN}$ in tendon force of internal tendon (bonded), while at the anchor, the increase was only $0.083 \mathrm{kN}$. For the 
TABLe 1: Characteristics of specimens.

\begin{tabular}{lccccc}
\hline Specimen & Concrete grade & Number of segments & Shear span ratio & Number of shear keys & Tendons \\
\hline 1 & C50 & 5 & 2.76 & 2 & Internal \\
2 & C40 & 5 & 2.76 & 3 & Internal \\
3 & C50 & 5 & 2.76 & 2 & Internal \\
4 & C50 & 5 & 3.09 & 2 & Internal \\
5 & C50 & 4 & 2.76 & 2 & Internal \\
6 & C50 & 5 & 2.76 & Internal and external \\
\hline
\end{tabular}
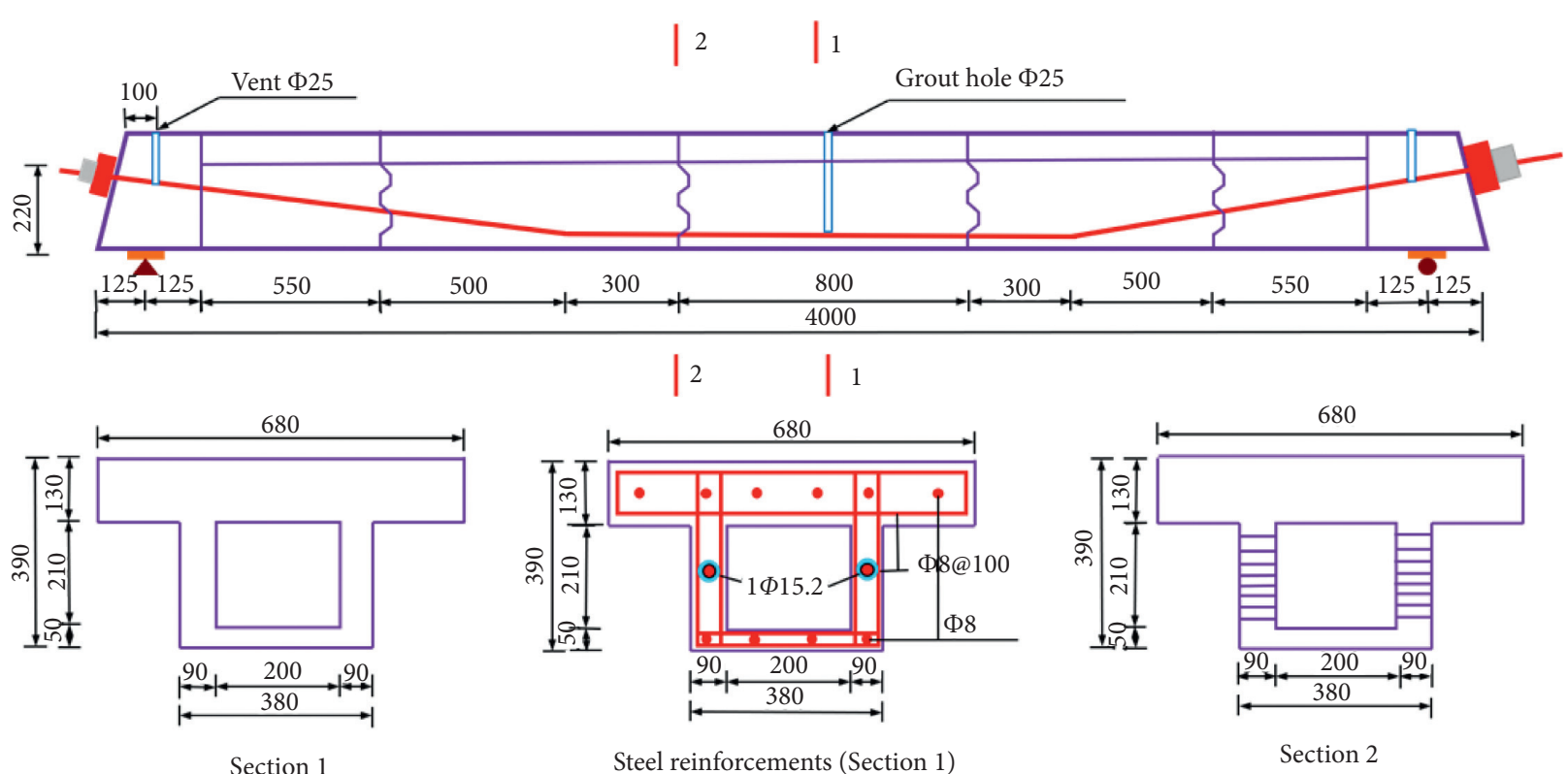

Steel reinforcements (Section 1)

Section 2
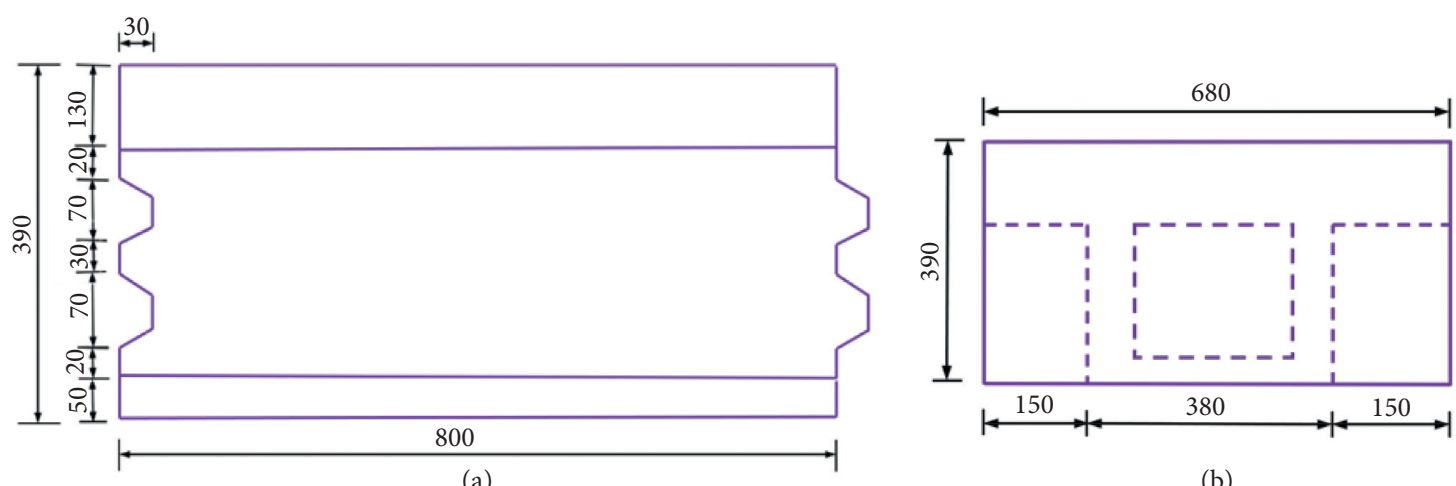

(b)

FIgURE 1: Specimen 1 (dimension unit: $\mathrm{mm}$ ) [21]: (a) profile of a segment; (b) section at support.

external tendon (unbonded) in specimen 6, the increase was $58.53 \mathrm{kN}$, which is basically identical to that of internal tendon at mid-span.

According to the load-deflection curves in Figure 7, specimen 4 showed the lowest flexural capacity among the six girders, showing the significant influence of the shear span ratio. The ultimate deflection of specimens 5 is much smaller than that of specimens 1 although the ultimate bearing capacities are close to each other. This is because specimen 5 has an even number of segments (i.e., four) and there was a segment joint at the girder mid-span, resulting in the reduction in local bending stiffness and larger tendon forces. Specimen 2 also showed comparatively smaller deflection at failure, due to its lower concrete strength that resulted in larger tendon force increments. In general, the flexural capacities of specimens 1,2,3, and 5 are close to each other. The ultimate bearing capacity of specimen 6 is significantly higher than that of the others as there were more tendons; accordingly, the deflection at failure was comparatively small since the stiffness of specimen 6 is very large.

Figure 8 demonstrates the change in concrete strains obtained from the strain gauges embedded near the bottom 


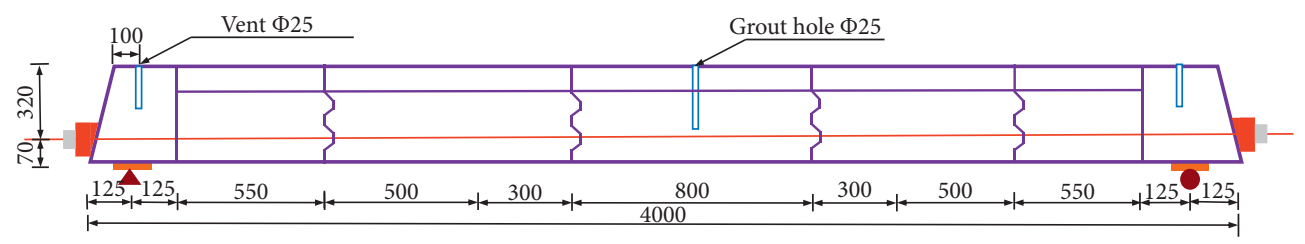

FIgURE 2: External tendons in specimen 6.

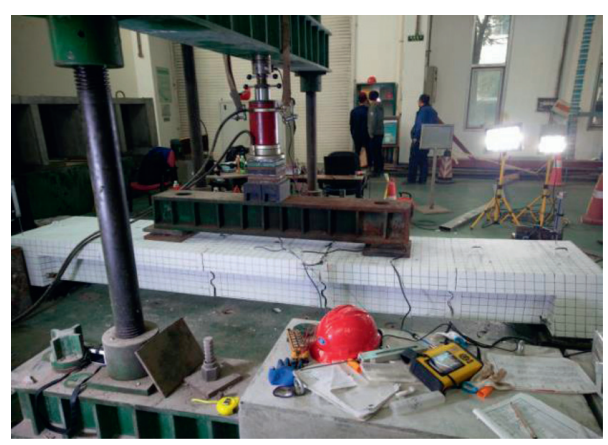

Figure 3: Two-point loading.

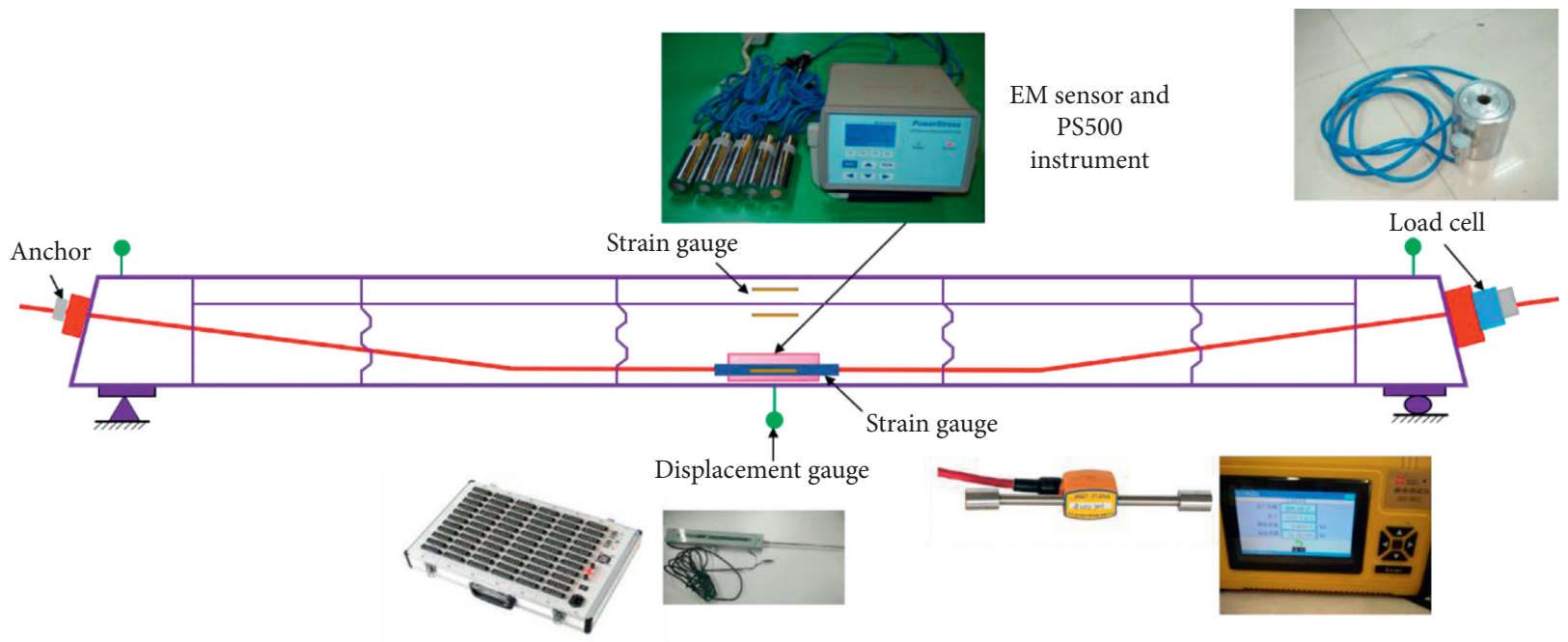

Figure 4: Layout of measuring points.

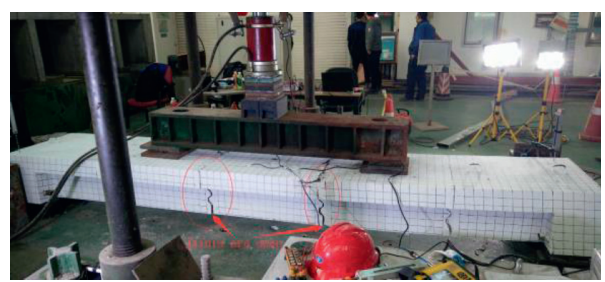

(a)

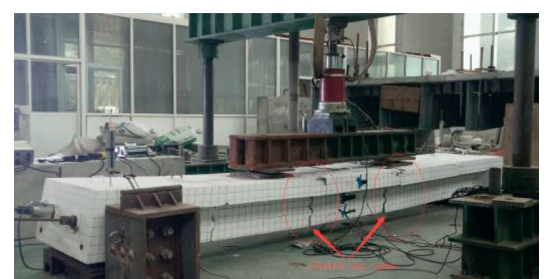

(b)

Figure 5: Specimens under the final step loading: (a) specimen 1; (b) specimen 4.

of the girders at the mid-span. In general, the strain increments of specimens 2 and 4 are much larger than those of the others, as shown in Figure 8(a), indicating that the concrete grade and span ratio significantly affect the strain increments. Specimen 4 showed a sudden drop in strain increments during the final load step, which was probably due to the concrete tensile fracture near the mid-span of the girder. The strain increments in specimen 3 were close to 
TABLE 2: Original and ultimate tendon forces.

\begin{tabular}{lcc}
\hline Specimen & Original tendon force $(\mathrm{kN})$ & $\begin{array}{c}\text { Ultimate tendon } \\
\text { force }(\mathrm{kN})\end{array}$ \\
\hline 1 & 118.52 & 243.72 \\
2 & 120.28 & 258.79 \\
3 & 120.64 & 243.72 \\
4 & 98.64 & 238.02 \\
5 & 108.36 & 238.24 \\
6 & 100.20 & 156.02 \\
\hline
\end{tabular}

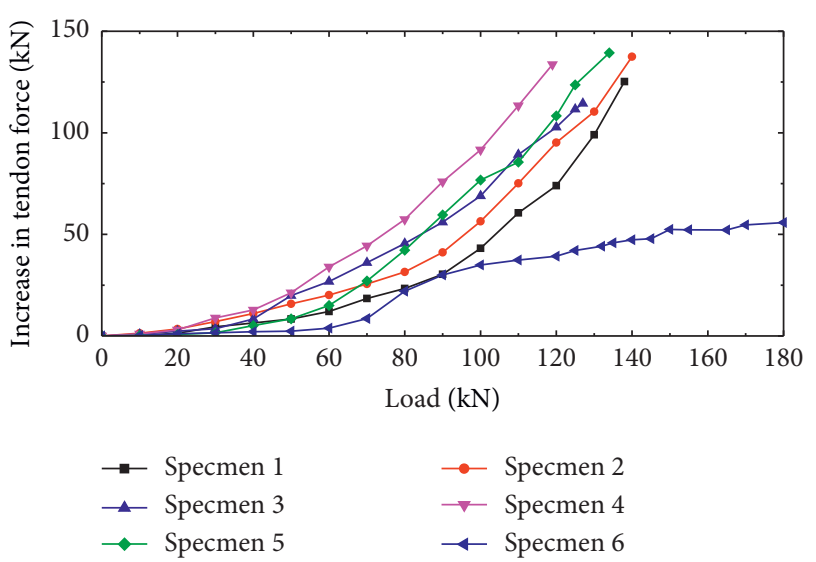

FIgURE 6: Increase in tendon forces during loading.

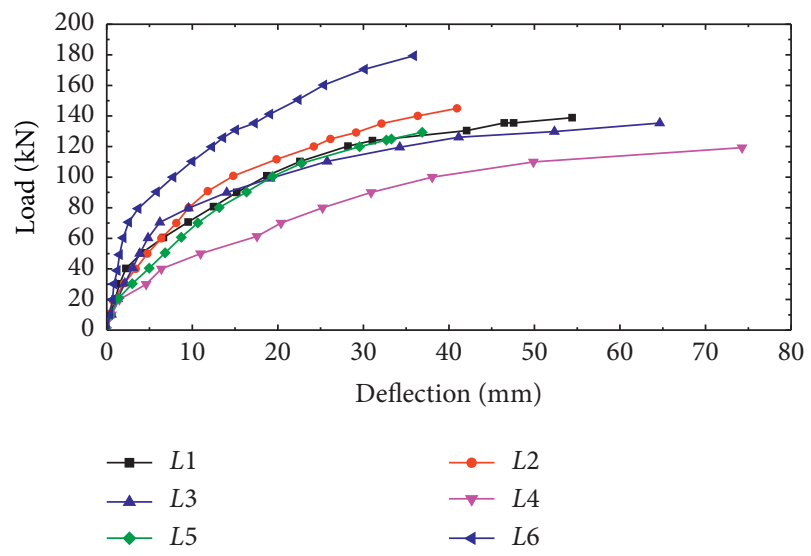

Figure 7: Load and deflection relationships.

those in specimen 1 (both were comparatively small), showing that the number of shear keys has an insignificant influence on strain increments, and specimens 1 and 3 have relatively smaller strain increments. Specimen 5 has slightly larger strain increments than specimens 1 and 3 , which is probably due to the fact that this specimen has four segments and the joint coincides with the mid-span section, which weakened the local stiffness. For specimen 6 with hybrid tendons, the external tendons increased the bearing capacity significantly, as shown in Figure 8(b); accordingly, the strain increments kept increasing to $400 \mu \varepsilon$ in the final step. Such a large increment is due to that larger initial compressive stress existed in specimen 6 since there were another two external tendons.
Figure 9 shows the strain distribution along girder heights of specimen 1 , where values under different load levels (i.e., 30, 60, 90, and $120 \mathrm{kN}$ ) were recorded. Two cross sections were selected for measurements, i.e., the mid-span cross section (section 1) and the cross section near shear keys (section 2, with a distance of $400 \mathrm{~mm}$ to mid-span), as shown in Figure 1. As the loads increased, the height of the compressive zone decreased and the neutral axis shifted upward, while the assumption of the plane section was kept prior to the load of $60 \mathrm{kN}$. Thereafter, significant nonlinear strain distributions were observed, which is due to the gradual opening of joints. It is also found that the compressive strains increased faster in Figure 9(b) than those in Figure 9(a), which is due to the existence of shear joints that weakened the cross section and high normal stiffness between shear keys.

The initial cracking loads of specimens 1 to 6 were $40 \mathrm{kN}$, $36 \mathrm{kN}, 30 \mathrm{kN}, 20 \mathrm{kN}, 30 \mathrm{kN}$, and $60 \mathrm{kN}$, respectively. It is found that specimen 4 with larger shear span ratio and specimen 6 with hybrid tendons had the smallest and largest cracking loads, respectively. Lower concrete strength, even number of segments, and more shear keys resulted in lower initial cracking loads.

Figures 10 and 11 show the crack distributions on the front and back profiles of specimens 1 and 5 , where cracks in specimen 1 were mainly at the joints in pure bending, while the cracking in the combined bending and shear zone were much fewer. However, for specimen 5, cracks are found at all three joints. Figure 12 further compares the cracking of top flanges of the two specimens, where concrete crushing in specimen 1 was observed at the joint near mid-span, while there were more cracks in specimen 5 but no crushing.

\section{Numerical Simulation and Parametric Analysis}

3.1. Numerical Modeling. The tested girders were modeled by using the finite element software DIANA, and the eightnode composite degenerated curved shell element CQ40S was used to simulate concrete element, as shown in Figure 13, which is capable of simulating the mechanical behavior of thin-walled post-tensioned concrete structures and facilitates modeling of embedded distributed reinforcement and bonded prestressed tendons [22]. The nonprestressed reinforcements in two perpendicular directions are automatically embedded in shell elements and modeled via reinforcement grid elements. The thickness of each layer of grid is determined according to the spacing and diameter of the steel reinforcements, and the location point defines the position of the grid in the thickness direction of the shell element. In CQ40S, the integration scheme over the element area is a reduced $2 \times 2$ Gauss integration, while in the thickness direction, 3-point Simpson integration is applied [22].

Tendons shown in Figure 13(e) were modeled through the reinforcement bar element in DIANA, which are automatically generated and defined with a few location points and shape functions. DIANA searches the shell elements for the intersections of the tendons with the shell element 


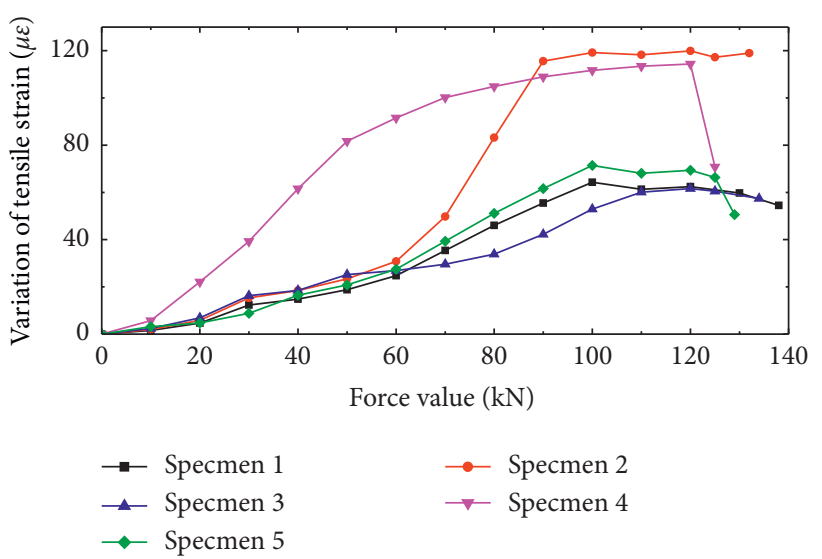

(a)

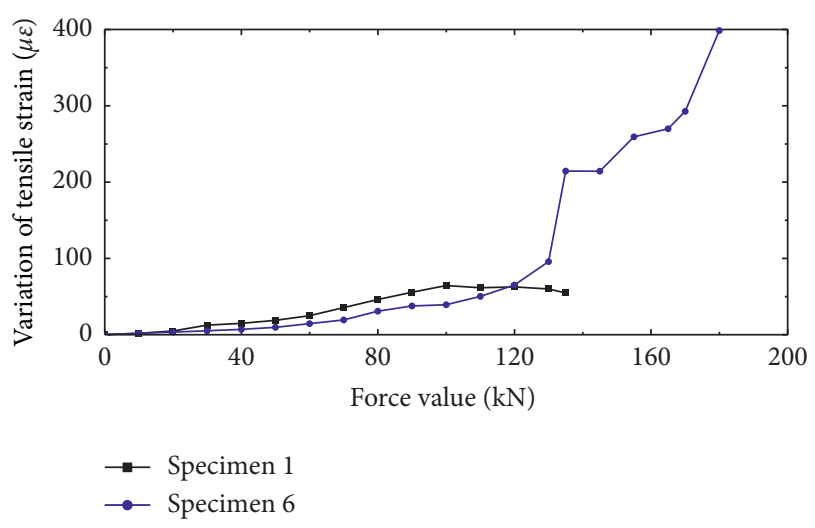

(b)

Figure 8: Change in strains of specimens 1 to 6:(a) specimens 1 to 5; (b) specimens 1 and 6.

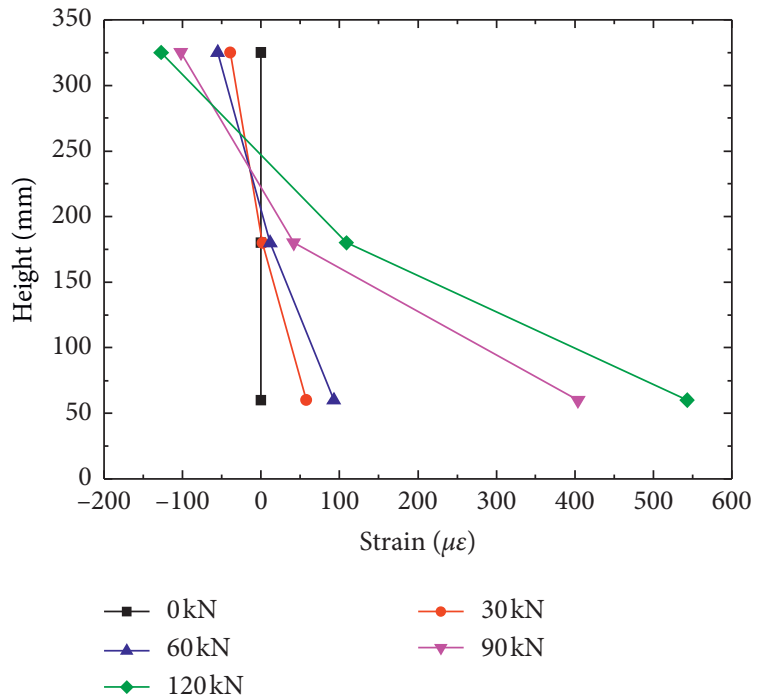

(a)

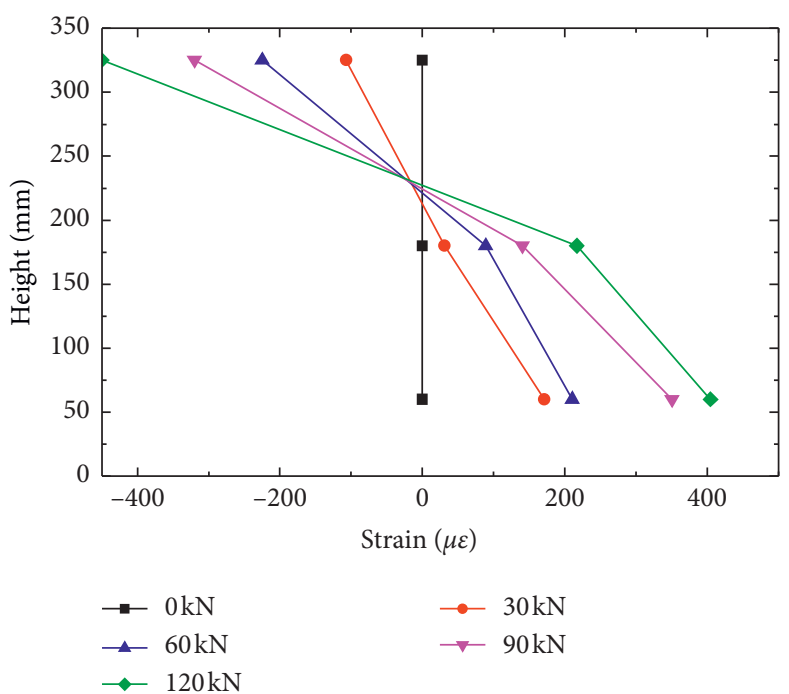

(b)

Figure 9: Strain distribution along girder heights (specimen 1): (a) mid-span cross section (section 1); (b) cross section near shear keys (section 2).

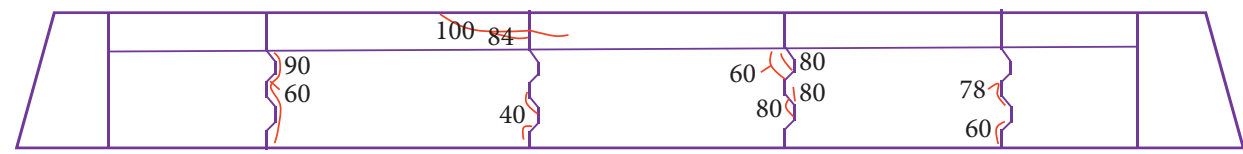

(a)

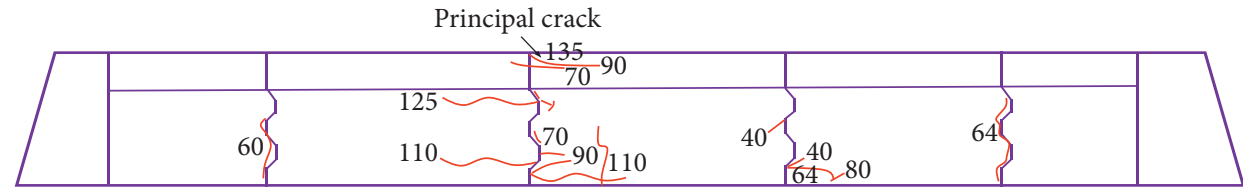

(b)

FIGURE 10: Crack distributions of specimen 1: (a) front profile; (b) back profile. 


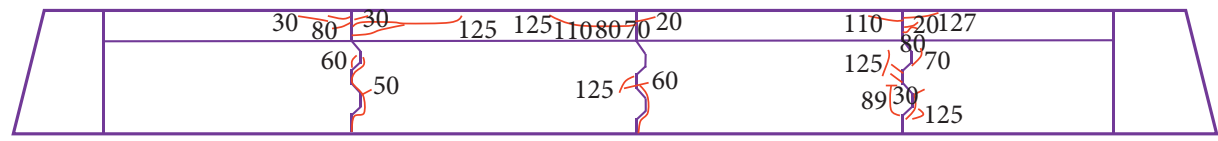

(a)

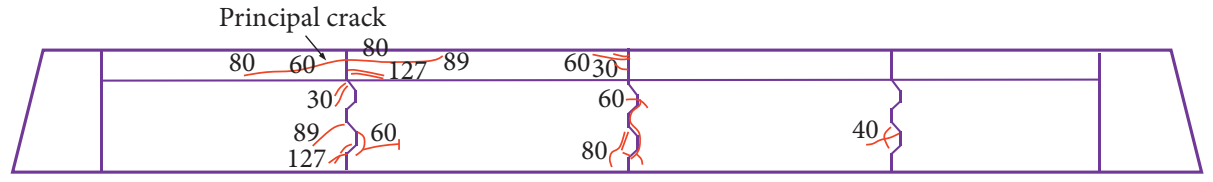

(b)

FIGURE 11: Crack distributions of specimen 5: (a) front profile; (b) back profile.

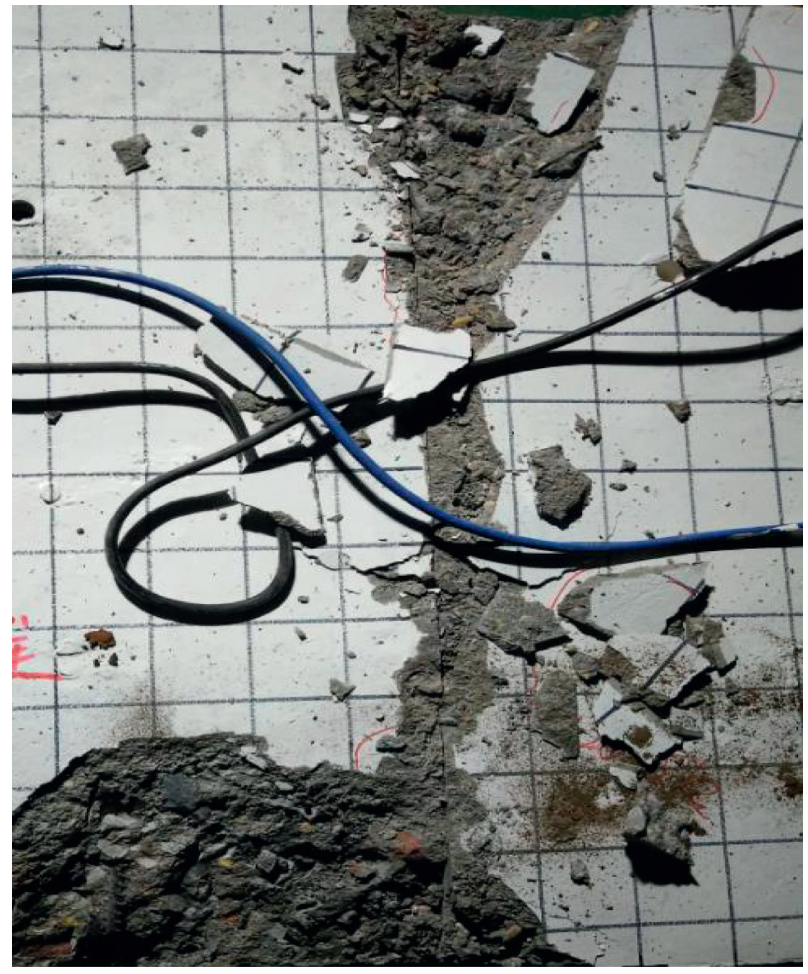

(a)

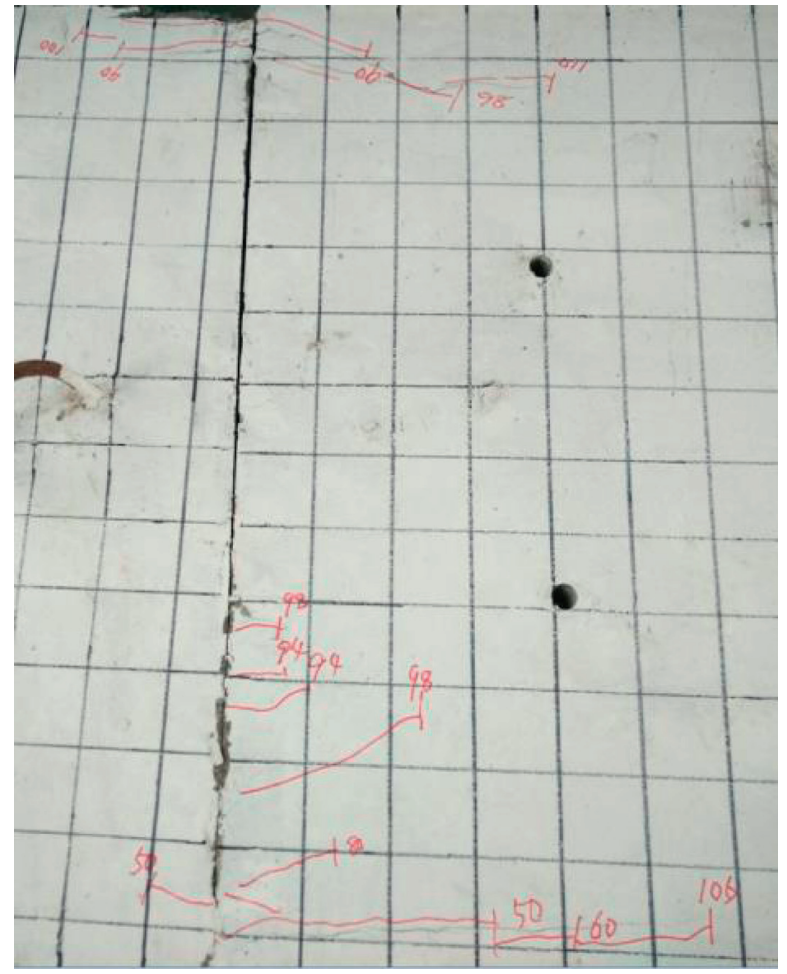

(b)

Figure 12: Cracks on top flanges of specimens 1 and 5 after the tests (plan view); (a) specimen 1; (b) specimen 5.

boundaries. These intersections serve as location points, which define the relationship of the tendons to their surrounding shell elements. The tendons are divided into segments by these location points, and the embedded tendons are constrained to the finite element mesh. They contribute stiffness to the FE model, and their strains are calculated from the displacement field of the mother shell elements, where the tendons are bonded to surrounding shell elements [22]. Each particle of a reinforcement bar is separately performed in DIANA, and the isoparametric element in the axis is divided for two particles in the numerical integration. Integration points are marked with a small triangle. In each integration point, DIANA determines an $\hat{x}$-axis tangential to the bar axis. The number of integration points is dependent on the element that the particle of the reinforcement bar is embedded in [23].
The interface element CL24I was applied for the simulation of shear key behaviors, which is a line to line connected interface element between edges of two curved shells [23] and works through the three couples of nodes on each element. The girder mesh and the internal bonded prestress tendons are shown in Figure 14.

3.2. Material Constitutive Model. In this study, the total strain-based crack model was selected to simulate the concrete crack propagation (DIANA 2008), which is defined according to the tensile and compressive concrete behaviors. According to whether the direction of crack is consistent with the direction of principal stress, the total strain-based crack model can be further divided into the fixed orientation-based crack model, the rotating orientation-based crack 


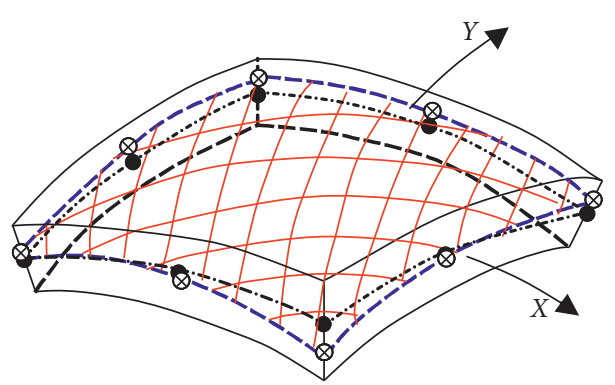

(a)

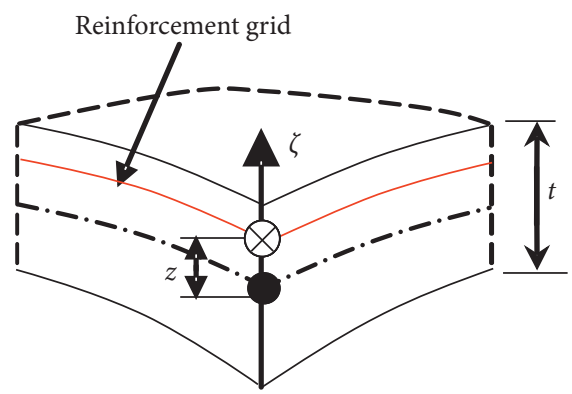

(c)

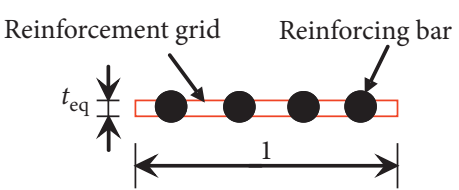

(b)

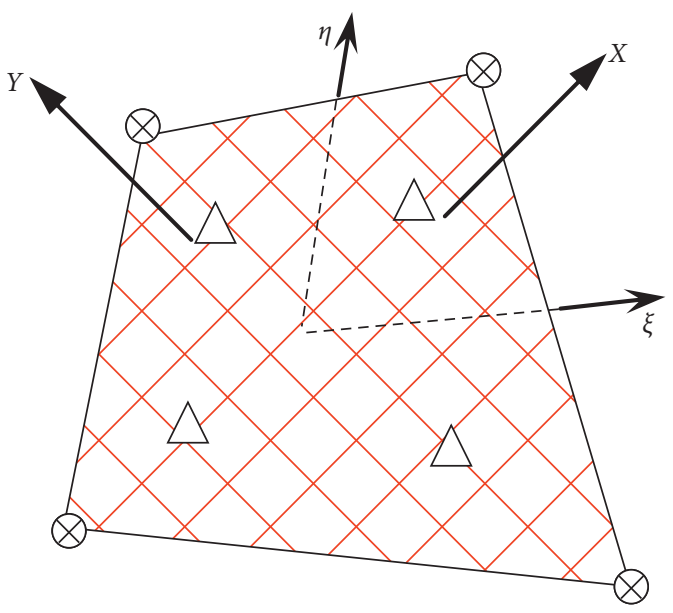

$\triangle$ Integration point

$\otimes$ Location point

Element node

(d)

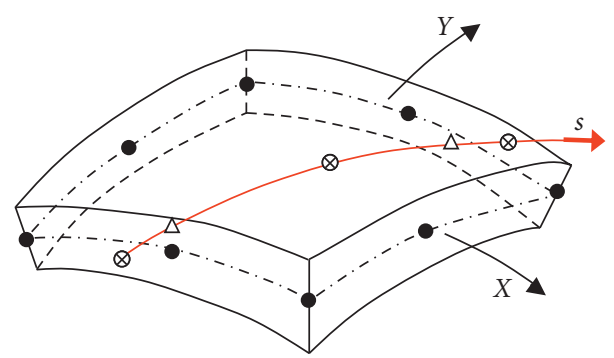

(e)

Figure 13: Composite degenerated shell element [22]: (a) composite shell element, (b) modeling of reinforcing bars via reinforcement grid, (c) location of reinforcement grid in the shell element, (d) segment of reinforcement, and (e) autogeneration of the tendon.

model, and the rotating to fixed orientation-based crack model. In this study, the rotating orientation-based crack model was selected. Meanwhile, the Rots model is chosen as the crack bandwidth specification. The Hordijk tensile softening curve, as shown Figure 15(a), was selected to simulate the tensile mechanism with the tensile strength 2.64 MPa coupled with Poisson's reduction model. In Figure 15(a), $f_{t}$ is the tensile strength while $G_{f}^{I} / h$ represents the tensile fracture energy per width unit with the unit $\mathrm{N} / \mathrm{m}$ or N/m in DIANA, which is MODE-I fracture energy. The compression curve adopts the fib 2010 compressive model, as shown in Figure 15(b) and the reduction model due to lateral cracking recommended in JSCE 2012 [24]. $f_{c}$ in Figure 15(b) represents the compressive strength, and the compressive strength of C50 and C40 is the same as the material test, which is $55.2 \mathrm{MPa}$ and $44.3 \mathrm{MPa}$, respectively.

Structural Shell Interfaces is chosen as line to line connected interface element class. The material model of interface elements between shells adopts the Coulomb friction in order to simulate the mechanical behaviors such as tension, contact, compression, and friction between segmental shear keys of dry joints under bending. The 3D line interface between shells in DIANA is selected with both the normal and shear stiffness modulus, respectively, and stiffness and mechanic behaviors of CL24I are shown as in Figures 16(a) and 16(b), respectively. Post-tensioned force is applied as load on the numerical model of tendons according to the measured value [21]. The Newton-Raphson iteration is adopted in the nonlinear analysis, 


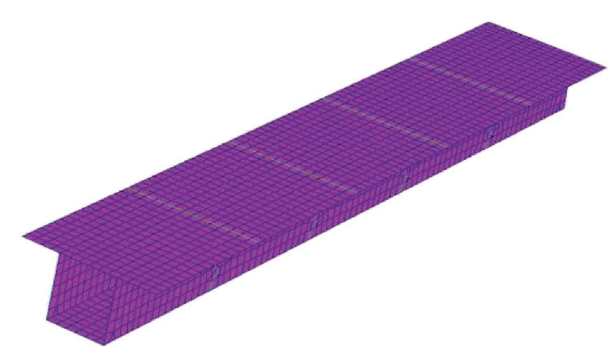

(a)

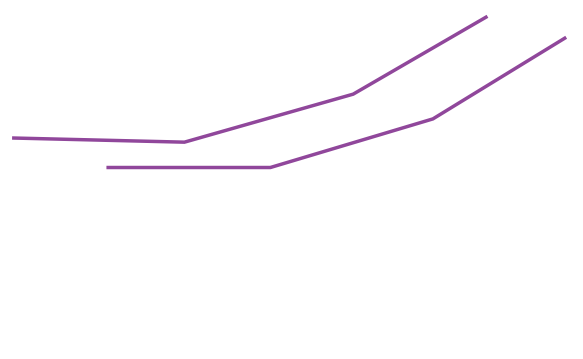

(b)

FIGURE 14: Numerical modeling of the test specimen: (a) finite element mesh; (b) tendons.

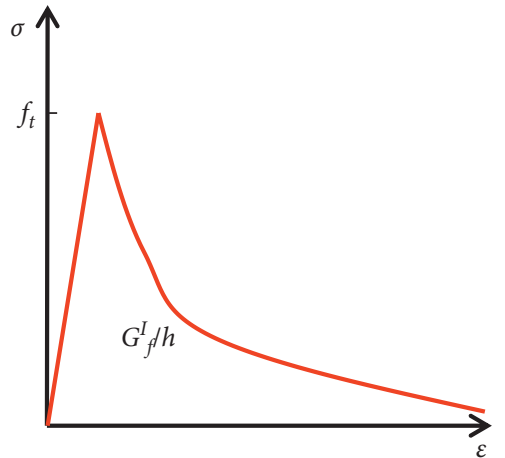

(a)

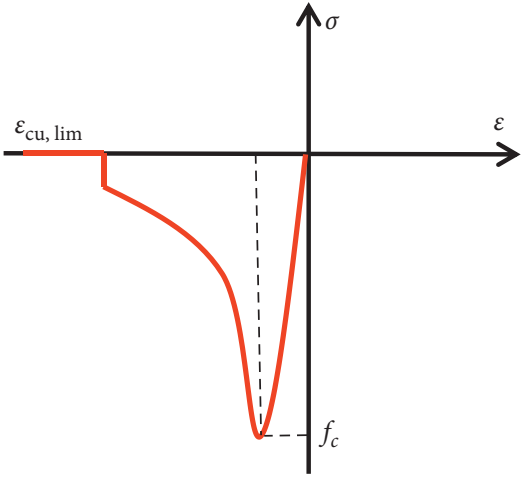

(b)

FIgURe 15: Constitutive models for tensile and compressive behavior in DIANA [24]: (a) tension softening model; (b) fib 2010 compressive model.

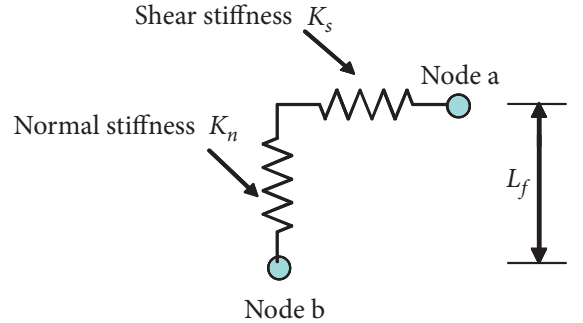

(a)

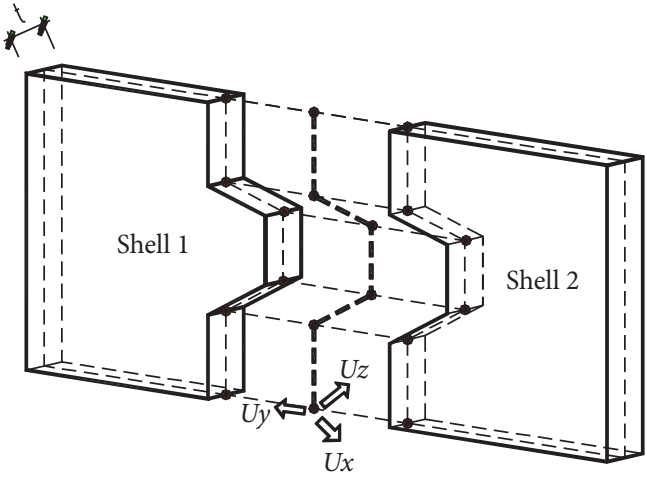

(b)

FIGURE 16: Line-to-line connected interface element CL24I [21]: (a) stiffness and nodes of CL24I; (b) mechanic behaviors of CL24I.

where force and displacement are combined as the convergence norm. The convergence tolerance is 0.001 , and the abort criterion is 10000 times. A step size of $10 \mathrm{kN}$ before $120 \mathrm{kN}$ and $5 \mathrm{kN}$ after that was used and the maximum number of iterations is 500 in each load step.

3.3. Numerical Simulation Results. Figures 17(a)-17(f) show the numerical simulation results, where the numerical simulation results are close to the test results, indicating the presented numerical modeling is capable of accurately simulating the girder behavior. Besides, Figures 18(a)-18(f) compare the increase in tendon forces, where the simulation match well with test results. Based on the validated models, parameters that are not considered in the tests are further investigated, including the thickness of top plate, the initial posttensioned prestress force, and the area of prestress tendon and another kind of joint (i.e., the corbel joint as shown in Figure 19). Other parameters and material constitutive models are the same as for specimen 1 . Table 3 summarizes the 

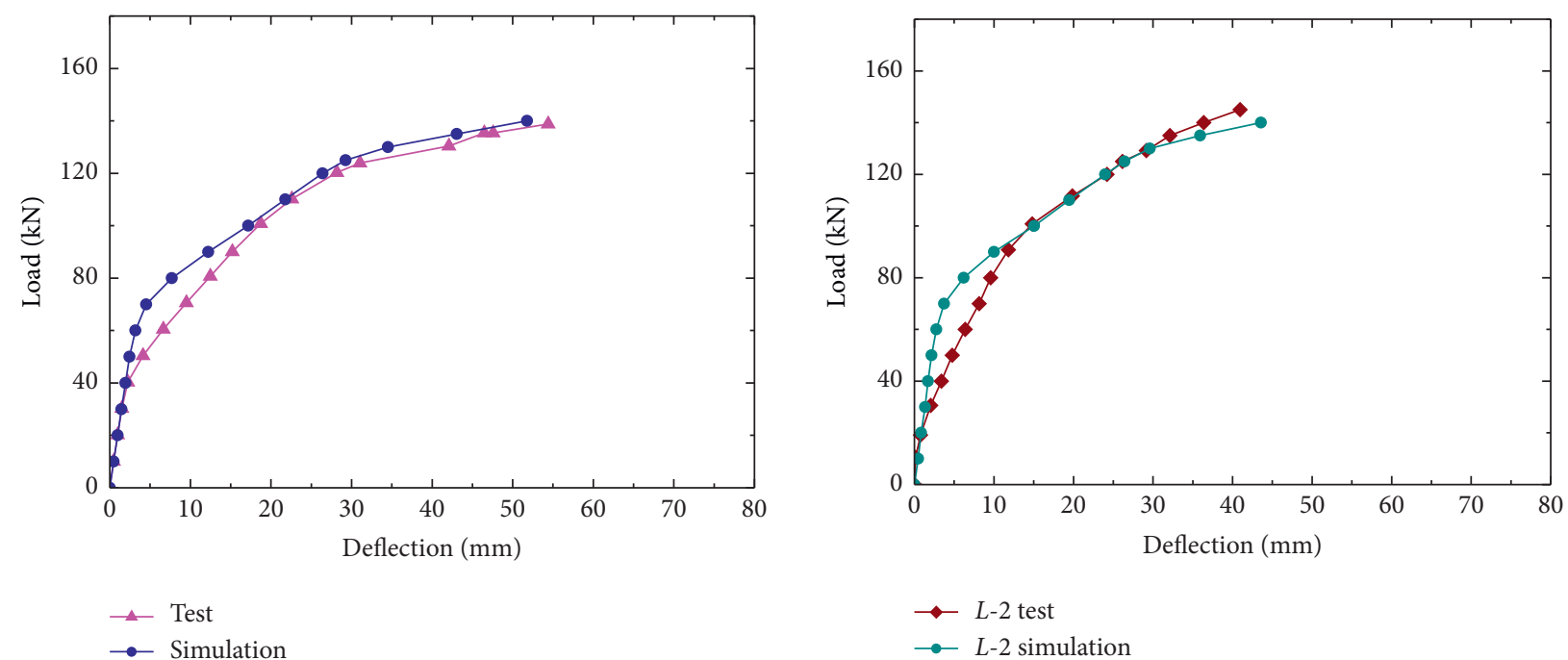

(a)

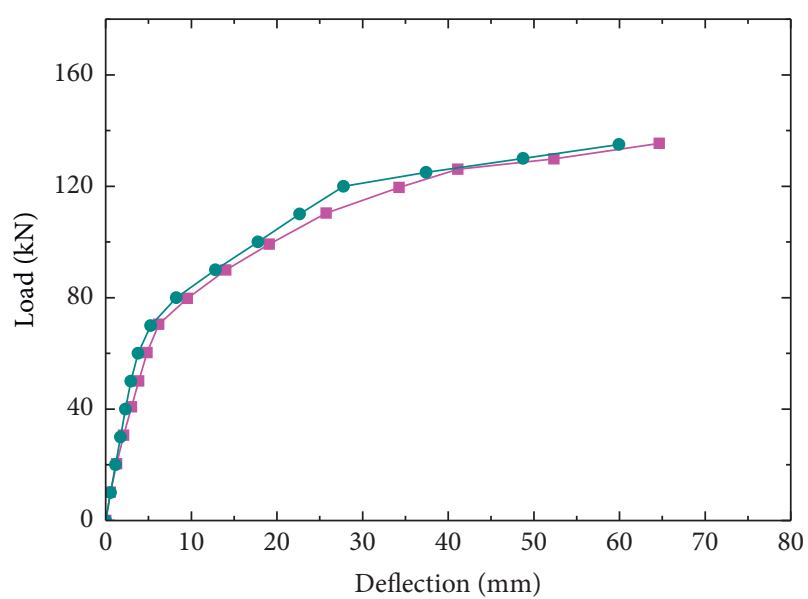

(b)

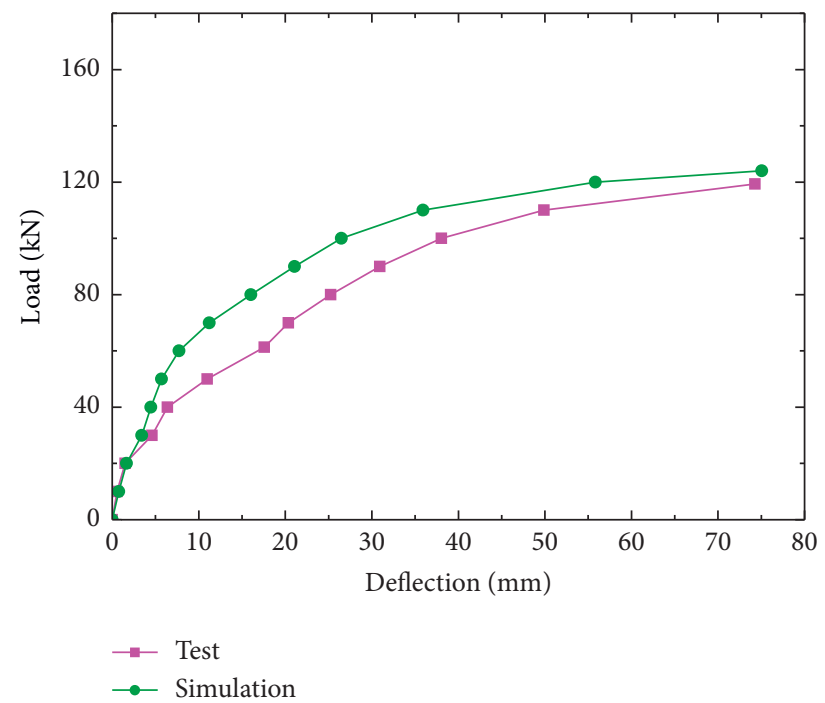

(c)

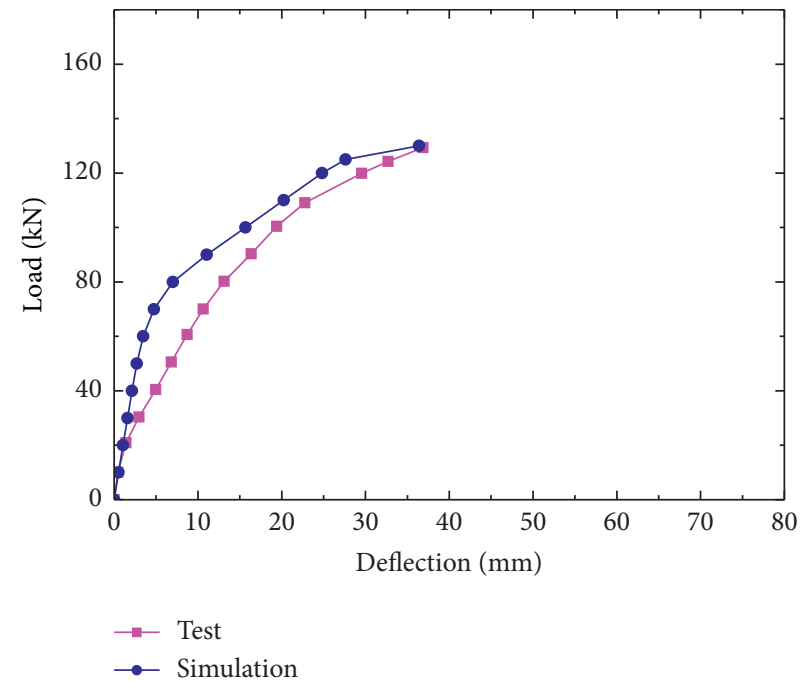

(e)

(d)

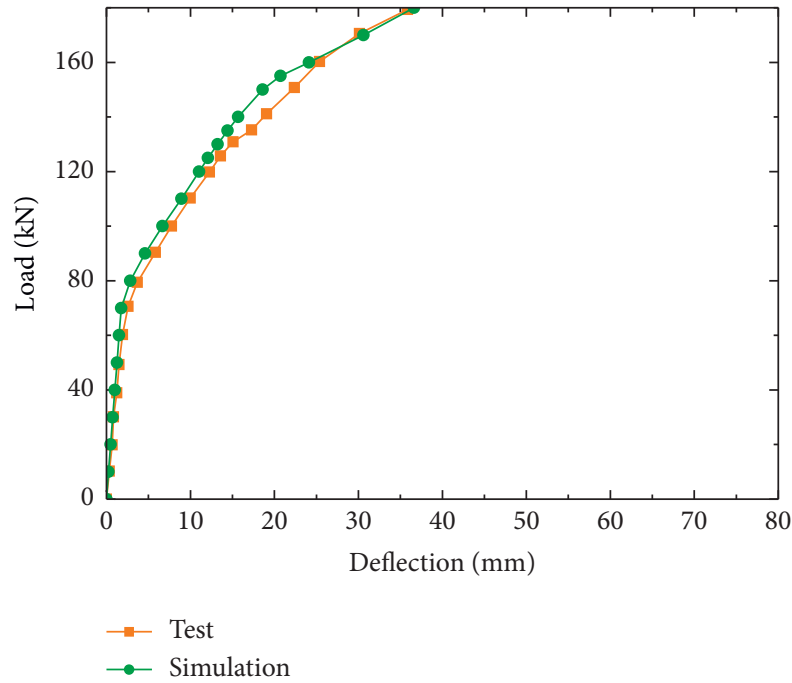

(f)

Figure 17: Comparison of test and numerical simulation results: (a) specimen 1, (b) specimen 2, (c) specimen 3, (d) specimen 4, (e) specimen 5, and (f) specimen 6. 


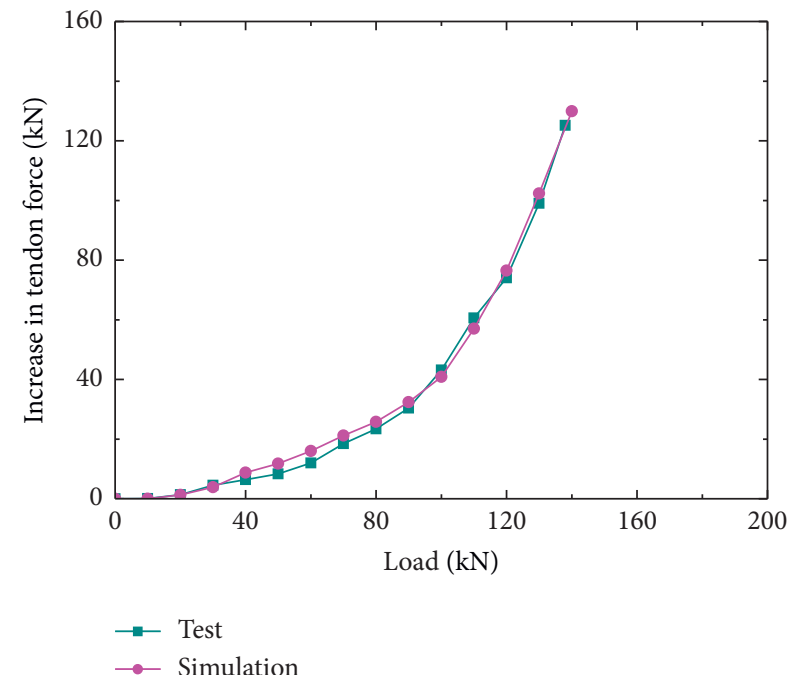

(a)

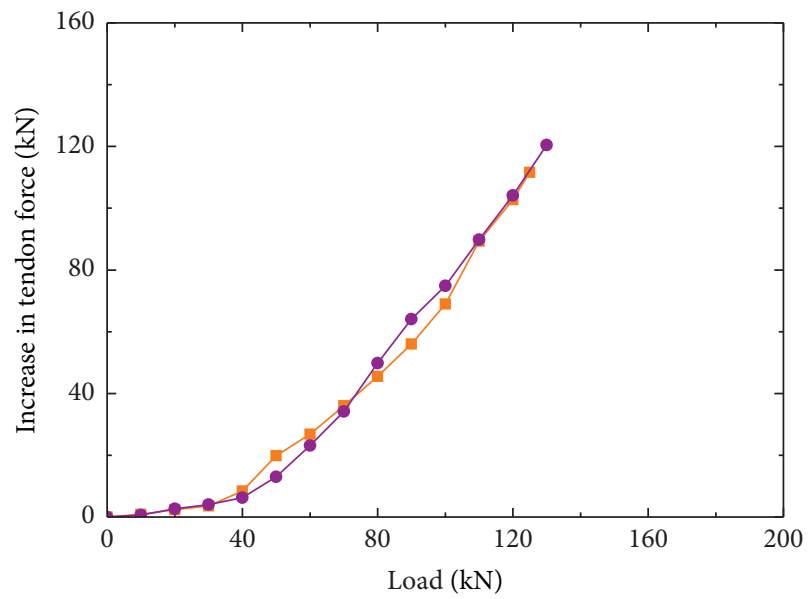

$\rightarrow$ Test

$\rightarrow$ Simulation

(c)

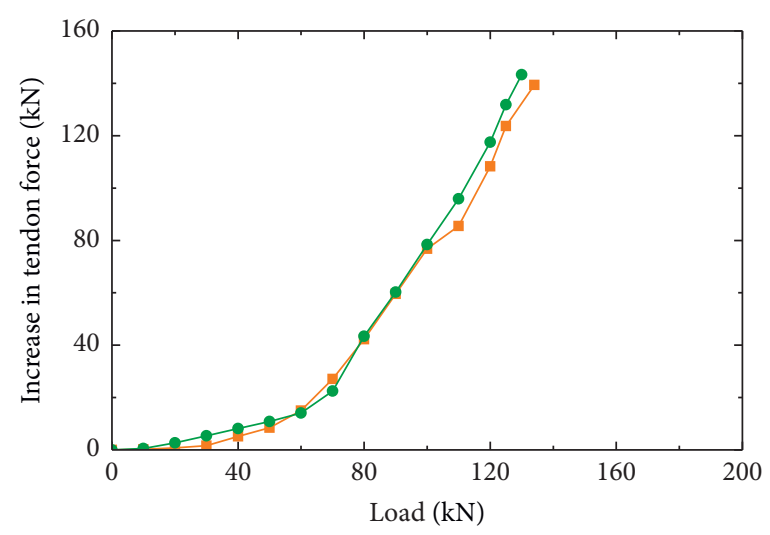

—- Test

$\rightarrow$ Simulation

(e)

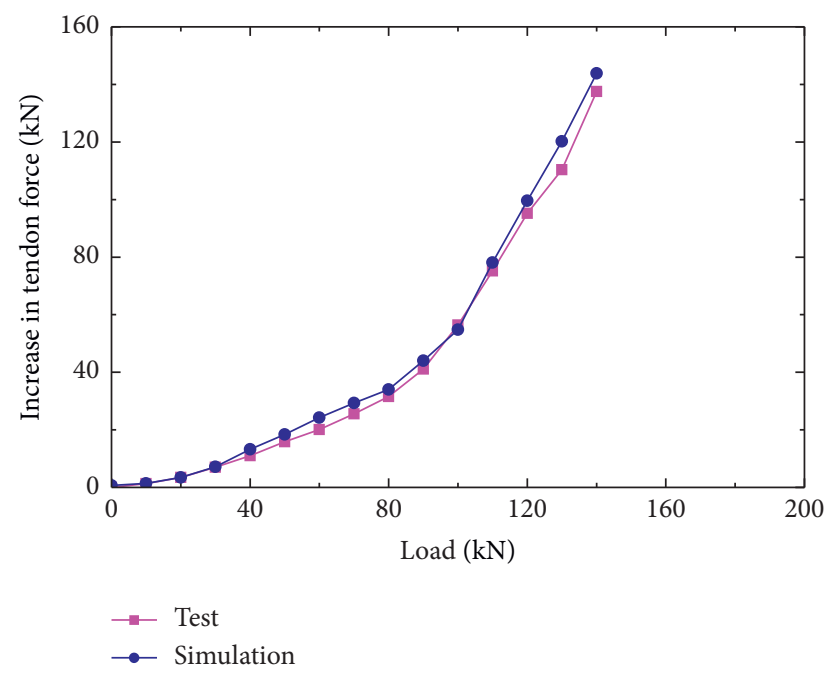

(b)

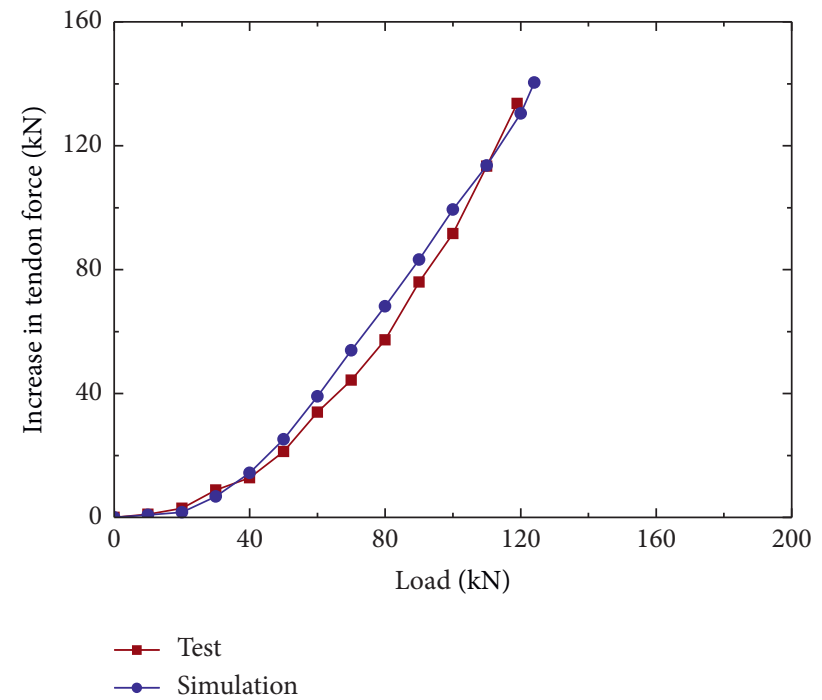

(d)

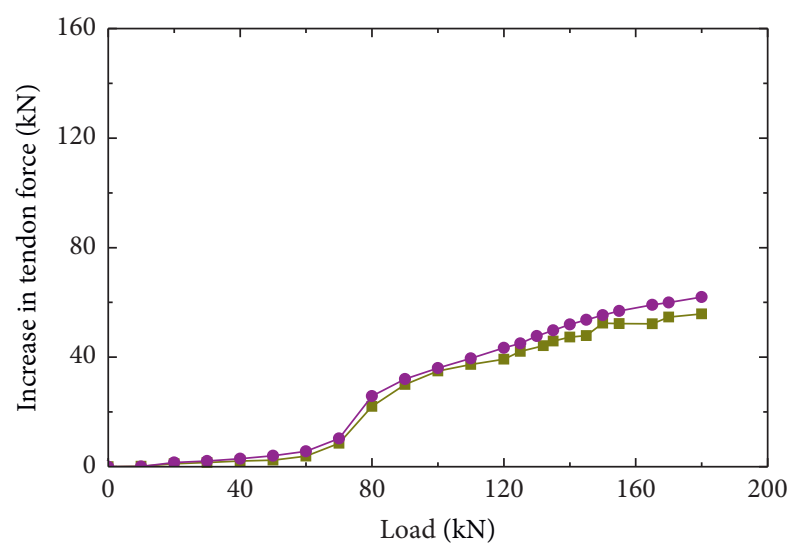

$\because$ Test

$\rightarrow$ Simulation

FIGURE 18: Comparison of test and numerical simulation results: (a) specimen 1, (b) specimen 2, (c) specimen 3, (d) specimen 4, (e) specimen 5, and (f) specimen 6 . 


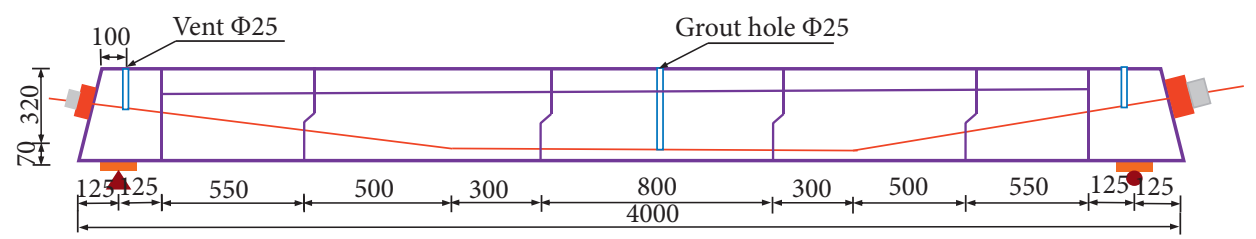

(a)

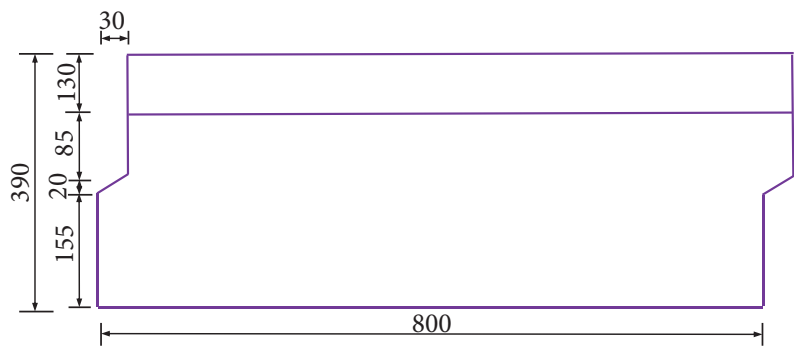

(b)

FIGURE 19: PCS girders with corbel joints.

TABLE 3: Characteristics of analysis cases.

\begin{tabular}{lcccc}
\hline Case & $\begin{array}{c}\text { Parameters } \\
\text { concerned }\end{array}$ & Value & $\begin{array}{c}\text { Ultimate } \\
\text { load }(\mathrm{kN})\end{array}$ & $\begin{array}{c}\text { Ultimate } \\
\text { deflection } \\
(\mathrm{mm})\end{array}$ \\
\hline 1 & $\begin{array}{c}\text { Integral casting } \\
\text { Castle-shaped } \\
\text { joint }\end{array}$ & 5 segments & 140 & 51.79 \\
2 & $\begin{array}{c}\text { Castle-shaped } \\
\text { joint }\end{array}$ & 4 segments & 130 & 36.4 \\
4 & $\begin{array}{c}\text { Corbel joint } \\
\text { Corbel joint }\end{array}$ & 5 segments & 145 & 58.68 \\
5 & $\begin{array}{c}\text { Thickness of } \\
\text { top plates } \\
6\end{array}$ & 100 mm & 135 & 49.58 \\
7 & $\begin{array}{c}\text { Area of } \\
\text { prestress } \\
\text { tendon }\end{array}$ & $104.25 \mathrm{~mm}^{2}$ & 100 & 34.94 \\
8 & Initial post- & $180 \mathrm{kN}^{2}$ & 140 & 43.64 \\
\hline
\end{tabular}

characteristics of these analysis cases; for comparison, the integral cast girder with continuous longitudinal steel reinforcements is also modeled. Analysis results are listed in Table 3 , and load-deflection curves of cases 1 to 5 are shown in Figure 20.

According to Table 3, compared with PCS girders, both the ultimate flexural bearing capacity and ultimate deflection of integral cast girder are significantly larger, with the increase of $82.14 \%$ and $64.52 \%$, respectively, mainly due to the continuity of longitudinal steel reinforcements. Besides, ultimate deflections of PCS girders with 4 segments tend to be lower than those with 5 segments. In addition, the change in initial posttensioned load and top plate thickness do not have a significant influence on the ultimate bearing capacity, while the reduced area of prestress tendon results in both far lower ultimate bearing capacity and ultimate mid-span deflection. As expected, when larger initial post-tensioned load is adopted, the ultimate deflection becomes significantly smaller, but the

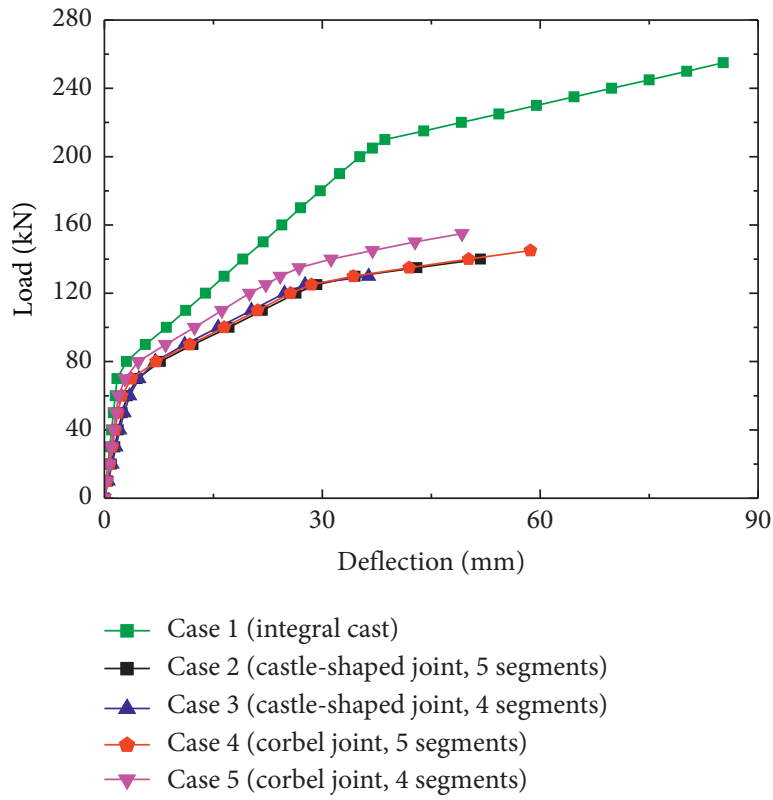

Figure 20: Load-deflection curves of cases 1 to 5 .

ultimate bearing capacity has an insignificant change. The corbel joints, in general, show better ultimate performance than the commonly used castle-shaped joints. This might be due to the fact that as compared with the castle-shaped joint, the corbel joint has less contact surfaces and has more uniform stress distribution under bending. On the other hand, the castle-shaped joint may have more complex stress distribution due to local compression under bending, resulting in concrete crush and loss in tendon forces.

\section{Conclusions}

This study investigates the flexural behavior of PCS box-girders with dry joints under bending loads, which has not been studied in 
depth previously. Based on the presented work, conclusions are drawn as follows:

(1) Specimens with only internal bonded tendons were failed under bending load due to the excessive force in tendons. Among them, larger shear span ratio had greater increase in tendon force and concrete strain during loading and, accordingly, the lowest flexural capacity. Lower concrete strength showed a significant increase in concrete strain and tendon force during loading, resulting in relatively smaller deflection at failure. With more shear keys, specimen 3 had only an insignificant influence on the girder behavior. However, for the specimen with 4 segments, a more significant increase in tendon force and small deflections at failure was observed, though the failure load was similar with specimen 1 .

(2) Specimen 6 adopted external tendons in addition to the internal ones; therefore, it had much larger flexural capacity and slower change in tendon force during loading; accordingly, the deflection at failure was the smallest. The failure of specimen 6 was due to the concrete crushing at top flanges, which is different from other specimens and is more similar to the over reinforcement failure.

(3) Larger shear span ratio and hybrid tendons resulted in the smallest and largest cracking loads, respectively, while lower concrete strength, even number of segments, and more shear keys could result in lower cracking loads. As compared with specimen 1, there were more cracks but no crushing in specimen 5 with four segments.

(4) Numerical simulation shows that the integral cast girder has larger ultimate bearing capacity and ultimate deflection compared with PCS girders. Accordingly, deflection control standard of PCS girders should be stricter than that of the integral cast girder. Besides, the changes in thickness of the top plate and initial post-tensioned force have an insignificant influence on the ultimate bearing capacity, while the area of prestress tendons significantly affects both ultimate capacity and ultimate deflection. The corbel joints, in general, show better ultimate performance than the commonly used castle-shaped joints.

\section{Data Availability}

The data used to support the findings of this study are available from the corresponding author upon request.

\section{Conflicts of Interest}

The authors declare that they have no known conflicts of interest or personal relationships that could have appeared to influence the work reported in this paper.

\section{Acknowledgments}

This research was funded by the Ministry of Science and Technology of the People's Republic of China under Grant no. 2016YFC0701400, the National Natural Science Foundation of China under Grant no. 51908191, and China Postdoctoral Science Foundation under Grant no. 2019M660103.

\section{References}

[1] X. Zhou, N. Mickleborough, and Z. Li, "Shear strength of joints in precast concrete segmental bridges," ACI Structural. Journal, vol. 102, no. 1, pp. 3-11, 2005.

[2] O. Buyukozturk, M. M. Bakhoum, and S. Michael Beattie, "Shear behavior of joints in precast concrete segmental bridges," Journal of Structural Engineering, vol. 116, no. 12, pp. 3380-3401, 1990.

[3] M. Alcalde, H. Cifuentes, and F. Medina, "Influencia del número de llaves en la resistencia a cortante de juntas secas postensadas," Materiales de Construcción, vol. 63, no. 310, pp. 297-307, 2013.

[4] H. Purnomo, R. Nursani, S. Mentari, S. A. Rahim, and E. Tjahjono, "Numerical evaluation of the shear behavior of a metal shear key used in joining precast concrete segmental bridge girders without epoxy," International Journal of Technology, vol. 8, no. 6, pp. 1050-1059, 2017.

[5] G. H. Ahmed and O. Q. Aziz, "Influence of intensity \& eccentricity of posttensioning force and concrete strength on shear behavior of epoxied joints in segmental box girder bridges," Construction and Building Materials, vol. 197, pp. 117-129, 2019.

[6] Z. Liu, Conceptual Design and Analytical Theory of Bridges, China Communication Press, Beijing, China, 2010, in Chinese.

[7] A. Yuan, Y. He, H. Dai, and L. Cheng, "Experimental study of precast segmental bridge box girders with external unbonded and internal bonded posttensioning under monotonic vertical loading," Journal of Bridge Engineering, vol. 20, no. 4, Article ID 04014075, 2015.

[8] H. Jiang, Q. Cao, A. Liu, T. Wang, and Y. Qiu, "Flexural behavior of precast concrete segmental beams with hybrid tendons and dry joints," Construction and Building Materials, vol. 110, pp. 1-7, 2016.

[9] G. Li, D. Yang, and Y. Lei, "Combined shear and bending behavior of joints in precast concrete segmental beams with external tendons," Journal of Bridge Engineering, vol. 18, no. 10, pp. 1042-1052, 2013.

[10] J. Kim, W. Chung, and J.-H. Jay Kim, "Experimental investigation on behavior of a spliced PSC girder with precast box segments," Engineering Structures, vol. 30, no. 11, pp. 3295-3304, 2008.

[11] J. Turmo, G. Ramos, and A. C. Aparicio, "Shear strength of dry joints of concrete panels with and without steel fibers: application to precast segmental bridges," Engineering Structures, vol. 28, no. 1, pp. 23-33, 2006.

[12] H. Jiang, R. Wei, Z. J. Ma, Y. Li, and Y. Jing, "Shear strength of steel fiber-reinforced concrete dry joints in precast segmental bridges," Journal of Bridge Engineering, vol. 21, no. 11, Article ID 04016085, 2006.

[13] P. Jongvivatsakul, L. V. Bui, T. Koyekaewphring, A. Kunawisarut, N. Hemstapat, and B. Stitmannaithum, "Using steel fiber-reinforced concrete precast panels for strengthening in shear of beams: an experimental and analytical investigation," Advances in Civil Engineering, vol. 2019, Article ID 4098505, 18 pages, 2019.

[14] H. Jiang, Y. Chen, A. Liu, T. Wang, and Z. Fang, "Effect of high-strength concrete on shear behavior of dry joints in 
precast concrete segmental bridges," Steel and Composite Structures, vol. 22, no. 5, pp. 1019-1038, 2016.

[15] Y. J. Kim, W. J. Chin, and S. J. Jeon, "Interface shear strength at joints of ultra-high performance concrete structures," International Journal of Concrete. Structures and Materials, vol. 12, no. 1, pp. 767-780, 2018.

[16] J. Turmo, G. Ramos, and A. C. Aparicio, "Shear behavior of unbonded post-tensioned segmental beams with dry joints," ACI Structural Journal, vol. 103, no. 3, pp. 409-417, 2006.

[17] V. Oettel and M. Empelmann, "Structural behavior of profiled dry joints between precast ultra-high performance fiber reinforced concrete elements," Structural Concrete, vol. 20, no. 1, pp. 446-454, 2019.

[18] T. D. Le, T. M. Pham, H. Hao, and Y. Hao, "Flexural behaviour of precast segmental concrete beams internally prestressed with unbonded CFRP tendons under four-point loading," Engineering Structures, vol. 168, pp. 371-383, 2018.

[19] L. Segura-Castillo, N. García, I. Rodríguez Viacava, and G. Rodríguez de Sensale, "Structural model for fibre-reinforced precast concrete sandwich panels," Advances in Civil Engineering, vol. 2018, Article ID 3235012, 11 pages, 2018.

[20] S. T. Song, "Experimental study and theoretical analysis on bending and joint shear resistance of precast segmental box girder bridges of high-speed railway," $\mathrm{Ph} . \mathrm{D}$. thesis in Chinese, Dissertation, Southeast University, Nanjing, China, 2015.

[21] S. Chai, T. Guo, Z. Chen, and J. Yang, "Monitoring and simulation of long-term performance of precast concrete segmental box girders with dry joints," Journal of Bridge Engineering, vol. 24, no. 6, Article ID 04019043, 2019.

[22] T. Guo, R. Sause, D. M. Frangopol, and A. Li, "Time-dependent reliability of PSC box-girder bridge considering creep, shrinkage, and corrosion," Journal of Bridge Engineering, vol. 16, no. 1, pp. 29-43, 2011.

[23] DIANA, DIANA User's Manual-Element Library, Release 9.3, TNO Building and Construction Research, Holland, Europe, 2008.

[24] DIANA, DIANA User's Manual-Material Library, Release 9.3, TNO Building and Construction Research, Holland, Europe, 2008. 